
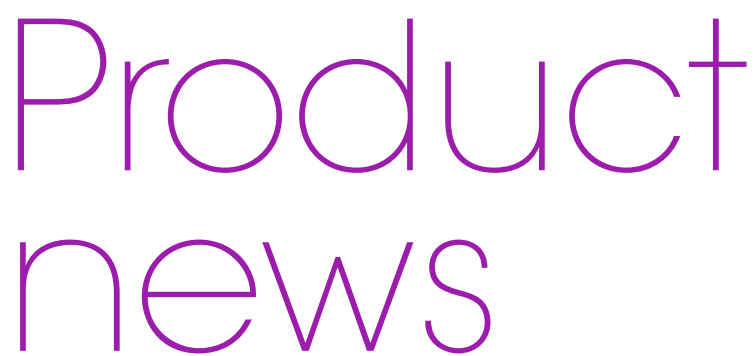

\section{A HIGHLY VALUABLE ORAL HEALTH SUPPLEMENT}

Help patients manage acute dental problems by recommending Perio Plus+ mouth rinse. This revolutionary new product offers the benefits of natural ingredients, proving to be more effective than market-leading chlorhexidine (CHX) solutions, thanks to its unique formula.

Perio Plus+ not only contains CHX, but also CITROX - a naturallv-derived substance that boasts potent anti-microbial, anti-oxidant, and anti-inflammatory properties. CITROX is combined with polylysine amino acids for enhanced efficacy and prolonged working time.

Moreover, Perio Plus+ ensures compliance through pleasant taste and minimal adverse side effects typically associated with traditional mouth rinses. This makes it a highly valuable supplement to routine tooth brushing and interdental cleaning.

Contact Curaprox for further details.

For more information call 01480862084 , email info@curaprox.co.uk or visit www. curaprox.co.uk.

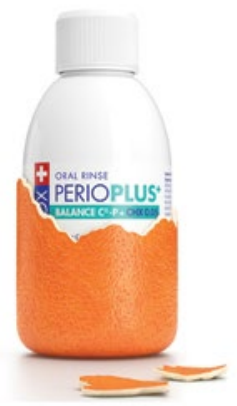

\section{IS YOUR AUTOCLAVE UPTO THE TASK?}

Your autoclave is an essential part of your everyday workflows. But is your current model up to the task?

The Little Sister SES 2020N autoclave from Eschmann has a number of features that ensure your staff don't feel the strain even when days get busy. The 17-litre capacity can hold five full-sized instrument trays, meaning that staff won't have to use the autoclave so often during the day and can concentrate on providing more attentive patient care.

Furthermore, with rapid cycles and active drying, instruments are ready to be used much faster!

Introduce a new era of efficiency into your practice by contacting Eschmann for more information today.

For more information on the highly effective and affordable range of decontamination equipment and products from Eschmann, visit www. eschmann.co.uk or call 01903875787.

\section{PRECISELY FITTING, DIGITALLY DESIGNED REMOVABLE PARTIAL DENTURES}

Offer your patients a thin, lightweight RPD frame made from Ultaire AKP for a natural, comfortable feel.

Ultaire AKP is a new generation, polymer-based material that has been custom developed by Solvay Dental 360. It provides patients with a viable alternative to metal, which is strong, durable and biocompatible.

RPDs fabricated from Ultaire AKP feature discreet clasp designs, which engage with undercuts and produce a snap-in fit to maintain excellent retention and outstanding aesthetic results. With the accuracy and design

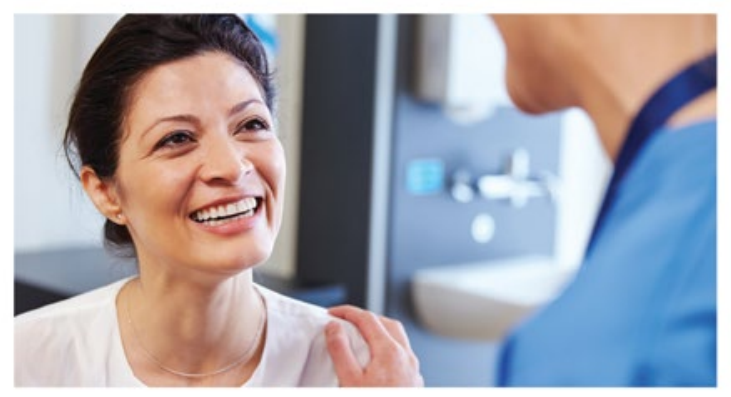
possibilities that can be achieved, Ultaire AKP is the way forward.

To book a Solvay Dental 360 Professional Lunch and Learn or to find more information about Ultaire AKP and Dentivera milling discs, visit www. solvaydental360.com. 